\title{
Conhecimento botânico e representações ambientais em uma comunidade rural no Domínio Atlântico: bases para conservação local
}

\author{
Gustavo Taboada Soldati ${ }^{1 *}$, Reinaldo Duque-Brasil ${ }^{2}$, Taline Cristina da Silva ${ }^{1}$, France Maria Gontijo \\ Coelho $^{3} \&$ Ulysses Paulino de Albuquerque ${ }^{1}$
}

${ }^{1}$ Laboratório de Etnobotânica Aplicada, Departamento de Biologia, Universidade Federal Rural de Pernambuco, Rua Dom Manoel de Medeiros, s.n., Dois Irmãos, 52171-900, Recife, Pernambuco, Brasil.

${ }^{2}$ Departamento de Biologia Vegetal e ${ }^{3}$ Departamento de Economia Rural. Universidade Federal de Viçosa, Viçosa, Minas Gerais, Brasil.

\begin{abstract}
Resumo - O presente texto busca contribuir para a construção de estratégias de conservação, valorizando as realidades específicas e o conhecimento das comunidades locais que manejam as paisagens. São apresentados os resultados de uma investigação etnobotânica sobre o conhecimento e as representações locais de uma comunidade rural sobre um fragmento florestal de Mata Atlântica, atualmente sobre proteção legal, em Viçosa, Minas Gerais. Os dados foram coletados junto a 26 parceiros, utilizando um conjunto de métodos etnobotânicos, como entrevistas semiestruturadas, listas livres, turnêsguiadas e mapas cognitivos. Foram reconhecidas 134 espécies, sendo Apuleia leiocarpa (Caesalpinaceae), Xylopia sericea (Annonaceae), Myrcia fallax (Myrtaceae), Ocotea odorifera (Lauraceae) e Piptadenia gonoacantha (Mimosaceae) as mais citadas. Os recursos foram distribuídos em seis categorias de uso, sendo "construção" a mais importante. A análise do Discurso do Sujeito Coletivo revelou o reconhecimento detalhado de uma variedade de processos ecológicos, como a diversidade de plantas, animais e fitofisionomias, interações entre espécies vegetais e a presença de bioindicadores. Os resultados representam uma caracterização inicial da relação entre a comunidade parceira da pesquisa e o fragmento florestal estudado, sendo um ponto de partida para a concepção de propostas de conservação da biodiversidade considerando a realidade local.
\end{abstract}

Palavras-chave adicinais: Conservação, etnobotânica, participação local, percepção ambiental.

\begin{abstract}
Botanical knowledge and environmental representations in a rural community in the Atlantic Domain: a basis for local conservation) - This paper aimed to contribute to building conservation strategies, evaluating specific realities and knowledge of the local communities that manage the landscape. In this ethnobotanical study, the knowledge of a rural community and the local concerns about an Atlantic Forest fragment, currently under legal protection, at Viçosa, Minas Gerais, are presented. Data from 26 participants was collected using a series of ethnobotanical methods, such as semistructured interviews, free lists, guided tours and cognitive maps. A total of 134 species were recognized. Apuleia leiocarpa (Caesalpinaceae), Xylopia sericea (Annonaceae), Myrcia fallax (Myrtaceae), Ocotea odorifera (Lauraceae) and Piptadenia gonoacantha (Mimosaceae) were the most recorded. Resources were divided into six use categories, and construction was the most important. The Collective Subject Discourse analysis about environmental concerns revealed a detailed knowledge of a variety of ecological processes, such as the diversity of plants, animals and vegetation types, plant interactions and the presence of bioindicators. The results provide an initial description of the relationship between the local community research partner and the forest fragment that was studied, being a starting point for the proposals to the biodiversity conservation considering the local reality.
\end{abstract}

Additional key words: conservation, environmental perception, ethnobotany, local participation.

Os remanescentes florestais de Mata Atlântica do estado de Minas Gerais abrigam uma alta diversidade biológica, geralmente concentrada em fragmentos isolados, que por sua vez estão submetidos a diversas pressões ambientais ou econômicas (Drummond et al. 2005). Tendo em mente a preservação dessa riqueza, diversas medidas foram propostas e executadas, tanto pelo Estado, Academia e/ou Terceiro Setor. Por exemplo, a declaração da UNESCO em 2002 reconheceu a Mata Atlântica como Reserva da Biosfera (RBMA 2010). Contudo, a grande maioria dessas medidas assume que a conservação nasce sobretudo pelo

\footnotetext{
*Autor para correspondência: gtsoldati@gmail.com Editora responsável: Cecília de Fátima C. B. Rangel de Almeida Recebido: 20 maio 2011; aceito: 6 jul. 2011.
}

manejo científico dessas áreas e o seu isolamento das atividades e ocupações humanas (ver Diegues 2000). Em contraposição a esta ideologia, muitos autores advogam que as práticas conservacionistas devem assumir um diálogo entre os diversos sistemas cognitivos (Academia e Popular) bem como, o reconhecimento de que a diversidade foi construída, manejada e preservada pelas populações locais (ver Toledo 1992; Diegues 2000; Albuquerque 2002). Nesse modelo ganha espaço e importância a participação das comunidades locais, junto com seus conhecimentos e formas de manejo.

Uma das pontes para se estabelecer um diálogo entre esses sistemas cognitivos são as investigações participativas junto às populações locais, que permitem registrar o conhecimento dos recursos, bem como as formas 
de manejo e preservação. Elas permitem avaliar as representações locais, identificando relações, expectativas, satisfações e insatisfações estabelecidas entre os moradores e o meio circundante (Guerra \& Abílio 2005), bem como as pressões externas que influenciam a perpetuação de seus valores e práticas. Essas informações permitem a construção de propostas conservacionistas mais complexas e contextualizadas às realidades específicas (Diegues 2000; Albuquerque 2002).

Diante do exposto, foi realizado um estudo etnobotânico sobre o conhecimento dos recursos vegetais e as representações locais de um fragmento florestal de Mata Atlântica. Especificamente, o presente estudo se propôs a: 1- registrar quais espécies vegetais existentes nas formações florestais são reconhecidas como recurso pela comunidade parceira da pesquisa; 2- avaliar alguns fatores que podem influenciar o conhecimento local sobre estes recursos; 3- compreender quais são as pressões que as comunidades do entorno da Reserva Mata do Paraíso estão submetidas; 4- discutir sobre as percepções locais dos parceiros da pesquisa em relação ao fragmento florestal e os seus aspectos ecológicos.

Seguindo as indicações Yildiz (1994) e Gumuchian \& Morais (2000), nesse trabalho o termo "representação local da paisagem" substitui o termo "percepção ambiental", pois este último ressalta a compreensão sensitiva dos indivíduos, sem levar em consideração fatores psicológicos, culturais e simbólicos, que também intervêm neste processo. Além disso, Cavalcante \& Maciel (2008) defendem que existe uma diferença entre tudo o que é percebido (subjetividade individual) e o que de fato pode ser externalizado (representação).

\section{Materiais e Métodos}

Área de trabalho. Esta investigação foi conduzida na Zona da Mata Mineira, região geopolítica que recebeu este nome pelas características da sua vegetação natural junto ao relevo rico em montanhas, com altitudes entre 200 e 900 m (Figura 1). Segundo a classificação proposta por Veloso et al. (1991), a vegetação desta região é classificada como Floresta Estacional Semidecidual Montana, caracterizada pela estacionalidade climática e pela mistura de espécies caducifólias e perenifólias. Entretanto, devido a um histórico de ocupação e utilização dos recursos naturais, pode se afirmar que uma das características da Zona da Mata é a carência de matas (Valverde 1958). As regiões de mata foram substituídas pelas culturas de subsistência, como feijão, batata, milho, cebola e, especialmente, o café.

$\mathrm{O}$ presente estudo foi desenvolvido no município de Viçosa (20 ${ }^{\circ} 45^{\prime} 14^{\prime \prime}$ 'S, $42^{\circ} 52^{\prime}$ '54”'W), estado de Minas Gerais, Sudeste do Brasil, localizado a aproximadamente $250 \mathrm{~km}$ da capital, Belo Horizonte. Pelas características do relevo, onde $85 \%$ de sua área corresponde a montanhas (Prefeitura de
Viçosa 2011), a agricultura na região, atividade econômica mais importante do município, se desenvolveu ao longo dos vales.

O conhecimento botânico local e suas representações, focos de investigação desta pesquisa, estão associados unicamente à Estação de Pesquisa, Treinamento e Educação Ambiental (EPTEA), também conhecida como Mata do Paraíso (Figura 1). Esse fragmento é o maior remanescente florestal da região, com 194,36 ha, situado a cerca de $6 \mathrm{~km}$ do centro urbano de Viçosa. Miranda et al. (1999) apresentaram o histórico do local, mostrando que a área de floresta foi explorada para a venda de recursos madeireiros e posterior utilização como pastagem e culturas agrícolas, comportando também atividade de uma pedreira de extração de brita. Posteriormente, a área deixou de ser propriedade particular e sua gestão passou a ser de responsabilidade da prefeitura de Viçosa, que utilizava a área para o abastecimento de água do município e como fonte de recursos madeireiros. Em 1966, a área passou a ser de inteira responsabilidade da Universidade Federal de Viçosa, sob a supervisão do Departamento de Engenharia Florestal (Miranda et al. 1999).

Atualmente, a vegetação é entendida como floresta secundária residual, composta por vários estágios sucessionais, formando um mosaico florestal (Silva 2003). Contudo, a partir do momento que o controle da reserva foi assumido pela Universidade as pressões reduziram. Porém, o fato dessa área ser limitada e protegida não inibe alguns eventos de apropriação de recursos naturais. A Mata do Paraíso é de extrema importância regional porque é uma das poucas áreas remanescentes que possui grande extensão de floresta nativa na região, e é considerada pelo estado de Minas Gerais como uma área de "alta importância biológica e carente de investigações científicas" (Drummond et al. 2005).

Comunidade estudada. O Palmital (Figura 1) é uma das seis comunidades que povoam o entorno da Mata do Paraíso, e exibe alguns traços remanescentes da cultura "caipira" que se desenvolveu em Viçosa principalmente pelo contato íntimo com a natureza. Como a mecanização agrícola não é possível na região devido ao relevo montanhoso, as atividades agrícolas estão vinculadas à subsistência ou visando o mercado local, como feiras. Alguns plantam milho, feijão, além de hortaliças, enquanto outros criam gado leiteiro. Existem vários aspectos e valores tidos como tradicionais, a saber: a utilização de carros-de-boi e engenho de pedra, o domínio de todas as etapas dos processos produtivos, a dependência dos ciclos naturais, a importância das relações de parentesco, e o fraco poder político. Em geral, as propriedades são pequenas e a redução da propriedade individual pelo processo de herança é marcante.

A comunidade está em contato frequente com o centro urbano. $\mathrm{O}$ transporte municipal acessa a comunidade quatro vezes ao dia, a maioria das crianças e adolescentes estuda 


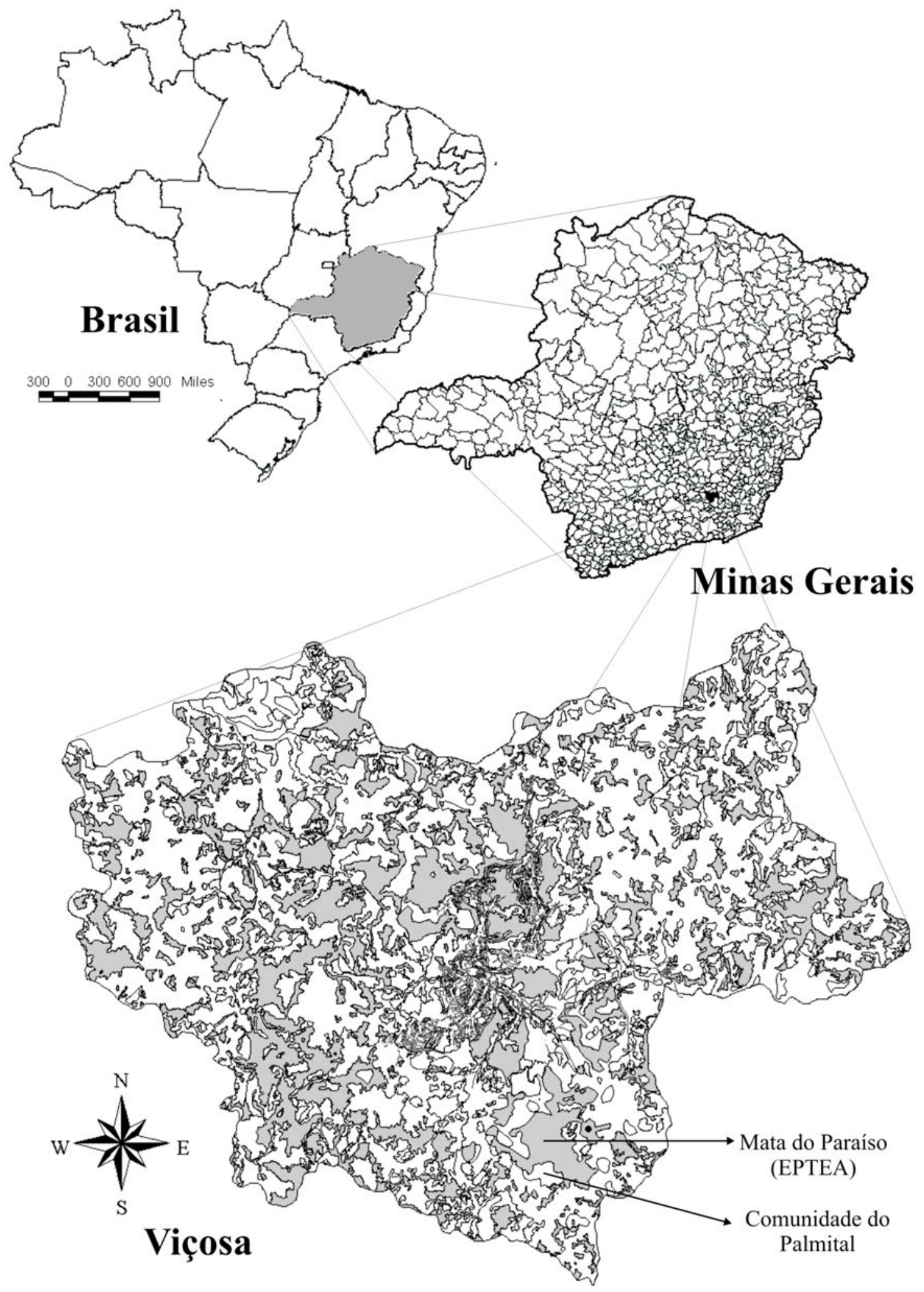

Figura 1. Localização da Mata do Paraíso (Estação de Pesquisa e Treinamento em Educação Ambientral - EPTEA) e da comunidade do Palmital, município de Viçosa, Zona da Mata Mineira (Fonte: Banco de dados do Laboratório de Geoprocessamento da Universidade Federal de Viçosa). 
em escolas do centro e alguns moradores exercem seu ofício na cidade. Além disso, alguns supermercados e farmácias do centro urbano entregam encomendas na comunidade. Existem algumas poucas propriedades que têm a finalidade de lazer e/ou produção, as quais os proprietários não nasceram e não moram em Palmital, na sua maioria professores da universidade. Não existem Associações ou Sindicatos de Trabalhadores Rurais na comunidade, tampouco coleta de lixo e água tratada. Dos 26 entrevistados, 20 nasceram na comunidade do Palmital, sendo que três moraram algum período em centros urbanos. Dos seis informantes que não nasceram na comunidade, cinco já moraram em outro local de Viçosa (quatro em outras zonas rurais e um no centro urbano) e um nasceu em outro município, também na Zona da Mata Mineira.

Todos os entrevistados são trabalhadores, sendo que a grande maioria (24) exerce atividades vinculadas ao cenário rural que habitavam e apenas dois informantes tinham atividades fora do meio rural. Não havia, dessa forma, relação patronal entre os moradores, ou seja, todos viviam do seu próprio trabalho.

Coleta de dados. Os primeiros contatos com a comunidade do Palmital foram mediados por uma moradora que trabalhava nas tarefas administrativas da EPTEA. A proposta inicial era desenvolver a técnica de amostragem "bola-de-neve" (Albuquerque et al. 2010a). Entretanto, o ciclo de indicações logo se fechou e sempre que havia a tentativa de ampliá-lo, entrevistando outros moradores, a técnica trazia novamente ao mesmo núcleo, composto por quatro informantes. Dessa forma, optou-se por seguir os trabalhos entrevistando os moradores em suas casas, conforme sua disponibilidade. As poucas residências pertencentes a professores da universidade, três no total, ou outros que apenas têm a propriedade como lazer, quatro no total, foram excluídas da amostragem, pois o objetivo principal foi caracterizar o conhecimento e as representações dos moradores que construíram e manejaram historicamente a paisagem e mantém relação com a Mata do Paraíso.

Os dados etnobotânicos foram coletados entre os meses de fevereiro e agosto de 2006, por meio de entrevistas semiestruturadas, gravadas com o consentimento dos informantes de acordo com a Resolução 196/96 do Conselho Nacional de Saúde (Viertler 2002; Albuquerque et al. 2010b). Essas aconteceram em três momentos distintos, para não cansar o informante, o que poderia enviesar os dados. No primeiro, o colóquio seguiu um formulário, constituído de perguntas concernentes à percepção do fragmento florestal e ao conhecimento dos recursos vegetais, relacionados às formações florestais, foco do estudo, bem como perguntas referentes a dados socioeconômicos (idade, sexo, atividade econômica mais importante, tempo de residência, dentre outras). Os informantes também foram convidados a construir, no próprio quintal, um desenho que explicitasse melhor a sua percepção da "mata". Para elucidar qual a influência e o conceito de "universidade" junto aos informantes, questões relacionadas à instituição foram também trabalhadas. No segundo encontro, foi solicitado ao informante que elencasse todas as plantas que conhecia e suas respectivas utilidades. Finalmente, quando necessária a revisão dos dados, seja para um enriquecimento ou elucidação das informações, realizou-se uma revisão das espécies listadas na lista livre junto com o parceiro da pesquisa em uma terceira ocasião.

As entrevistas foram aplicadas em um total de 26 moradores das 41 residências do universo proposto, perfazendo um total de $64 \%$ das moradas. No total, foram investigados 21 homens, com idades variando de 27 a 78 anos, e seis mulheres, com idade variando de 28 a 78 anos. Todos os moradores reconhecidos pelos seus pares por deter considerável conhecimento foram entrevistados, exceto um, que apresentava problemas de saúde. Foram realizadas, juntamente às entrevistas, sete turnês-guiadas em fragmentos florestais, com o intuito de elucidar e validar os nomes das plantas citadas nas entrevistas (Albuquerque et al. 2010a), quando se pôde coletar material botânico para a identificação científica. Os sete moradores foram escolhidos pelo respaldo que tinham da comunidade ou porque demonstraram, na entrevista, ser portadores de considerável conhecimento. As plantas coletadas foram herborizadas identificadas e depositadas no Herbário VIC da Universidade Federal de Viçosa.

Análise dos dados. Para uma melhor compreensão dos padrões de utilização, os recursos vegetais foram classificados em seis Categorias de Uso: alimentação, combustível, construção, medicinal, artefatos e outros e, sendo a última análoga a categoria "tecnologia" utilizada em outros trabalhos (Phillips \& Gentry 1993a; Mutchinick \& McCarthy 1997; Galeano 2000). Para determinar a importância cultural dessas categorias, foi calculado o Valor de Uso (VU) proposto por Phillips \& Gentry (1993a,b), sendo seguidas as modificações no índice propostas por Galeano (2000) e Lucena et al. (2007). A classificação das famílias botânicas seguiu Cronquist (1988).

Com os dados das entrevistas relacionados às representações sobre o fragmento de forma geral, fez-se a Análise do Discurso do Sujeito Coletivo, utilizando dados de suas representações em relação à mata (Silva et al. 2010). Para isso, foram extraídas as expressões-chave de cada resposta relacionada aos aspectos ecológicos do fragmento florestal, seguido do agrupamento das ideias centrais semelhantes para construção do discurso coletivo (Lefevre \& Lefevre 2005). Após esta análise, foi construída uma tabela de cognição comparada (Marques 1993) para cada aspecto relacionado ao fragmento florestal, a fim de realizar uma comparação entre os discursos dos informantes e as informações da literatura.

\section{Resultados e Discussão}

Conhecimento local dos recursos florestais. A comunidade do Palmital reconheceu no total 134 espécies existentes na "mata", sendo que destas, 129 apresentam 
alguma utilidade (Tabela 1). As 129 espécies úteis para a comunidade do Palmital pertencem a 39 famílias botânicas. Mimosaceae foi a família que mais apresentou espécies úteis, $10(8,84 \%)$ ao todo, seguida de Myrtaceae, Fabaceae, Bignoniaceae e Caesalpinaceae todas com sete espécies $(6,19 \%)$, e Moraceae e Euphorbiaceae contribuíram com seis representantes $(5,30 \%)$. Treze plantas foram citadas, mas por algum motivo, como inacessibilidade, ou extinção local, não foram coletadas, e portanto, não foram identificadas.

A comparação da riqueza de espécies citadas no presente estudo com outras investigações torna-se complicada por estas terem sido realizadas em contextos ambientais distintos e focarem, em sua maioria, apenas uma categoria de uso, notavelmente a categoria medicinal. Além disso, a presente pesquisa foi realizada tendo como foco apenas um dos ambientes reconhecidos pela comunidade do Palmital, no caso a "mata", o que certamente minimiza o volume de informação citado pelos parceiros.

Do total de espécies citadas, 94 foram reunidas na categoria de uso construção (16 destas exclusivas à categoria), 63 na categoria combustível (7 espécies exclusivas), 52 na categoria artefatos (6), 31 na categoria outros (8), 19 na categoria alimentação (6) e 15 espécies foram agrupadas na categoria medicinal (1 exclusiva) (Tabela 2). A comunidade somou 1120 citações, distribuídas em 115 usos distintos. A categoria construção destacou-se, apresentando 739 citações para 36 usos, sendo seguida da categoria combustível, com 133 citações para quatro usos, tecnologia, com 115 citações para 33 usos, e alimentação, com 47 citações para cinco usos.

Os dez usos mais citados e seus respectivos totais de citação foram: “estaca” (155), "lenha” (131), "tábua” (114), “caibro" (89), “esteio” (77), "ripa” (70), “móveis” (63), "régua" (48), "comer" (41) e "cabo de enxada" (33). Desses, apenas "comer" não é um uso madeireiro. Esses resultados evidenciaram a importância da categoria de uso construção e, consequentemente, dos recursos madeireiros para a comunidade do Palmital, posto que todos os usos dessa classe são dessa natureza.

A categoria medicinal teve o segundo maior Valor de Uso, ficando atrás apenas da categoria construção (Tabela 2). Isso se deu porque essa categoria recebeu um alto número de citações em relação à baixa riqueza de espécies. A categoria combustível foi a segunda mais citada, mesmo apresentando apenas quatro usos: "lenha", "carvão", "óleo" e "iluminação". Esta apresentou baixo Valor de Uso por ter uma alta riqueza de espécies.

Como no presente estudo, Cunha \& Albuquerque (2006) investigaram o conhecimento dos moradores locais sobre os fragmentos de Mata Atlântica, contudo, conduzida em Rio Formoso, Pernambuco. Na realidade investigada por estes autores, a categoria construção, junto com combustível, foi a mais rica em espécies. Na comunidade estudada por eles (Cunha \& Albuquerque 2006), a categoria medicinal também não apresentou muitas espécies e recebeu poucas citações de uso. Borges \& Peixoto (2009) registraram que a categoria construção/tecnologia foi a mais rica entre os moradores da comunidade caiçara no Rio de Janeiro. Apesar de terem sido conduzidos em áreas distintas, o presente estudo e os trabalhos de Cunha \& Albuquerque (2006) e Borges \& Peixoto (2009) sugerem que, para o Domínios Atlânticos, as zonas de mata são preferencialmente fonte de recursos madeireiros. O estudo de Hanazaki et al. (2000), também conduzido em áreas de Mata Atlântica, não corroboram esse possível padrão, mas é necessário salientar que os autores investigaram todo o conhecimento local e não apenas das áreas de mata nativa.

Essa mesma realidade não é verificada em outros domínios vegetacionais. Botrel et al. (2006) verificaram que as matas nativas de Cerrado oferecem para a comunidade local tanto um rico banco de espécies destinadas à construção como plantas destinadas à cura. Já para a realidade da Caatinga, Semiárido brasileiro, a situação se inverte, pois as áreas de mata nativa são potencialmente as zonas de maior preferência para a coleta de plantas medicinais (Albuquerque 2006). Este autor sugere que a preferência das áreas nativas para a coleta de plantas medicinais reflete uma estratégia adaptativa das áreas semiáridas que garante a coleta contínua desses recursos, pois nestas áreas os recursos medicinais de maior preferência, as cascas das árvores, estão disponíveis o ano todo.

A madeira (lenho apenas) e o caule são as partes da planta que receberam o maior número de usos e citações de uso (Tabela 3). Neste sentido, a utilização preferencial das espécies para a construção e das partes perenes remetem a uma discussão sobre a conservação da diversidade na EPTEA. Esta prática é altamente danosa às espécies e comunidades vegetais, o que potencializa a pressão de uso nesta zona de recurso.

As informações aqui expostas não garantem que existe uma pressão real sobre a Mata do Paraíso, pois as ferramentas metodológicas aqui utilizadas, em especial o Valor de Uso, não distinguem o uso potencial de sua exploração real. Os dados permitem apenas considerar que existe um uso potencial sobre as matas da região, e que sua exploração, quando ocorre, pode ser danosa às espécies. A vivência com a comunidade corrobora essa distinção entre o uso potencial (citado nas entrevistas) e o uso propriamente dito. Durante o trabalho de campo pôde-se identificar um cenário local de pouca pressão de uso sobre a EPTEA, sobretudo pelo fato dos moradores saberem que as matas estão atualmente protegidas pelas leis ambientais. Os parceiros da pesquisa afirmaram que não mais coletam espécies nestas zonas. Como resultado, as demandas atuais de madeira são supridas a partir de pequenas plantações de Eucaliptus sp. ("eucalipi") nas propriedades, chamadas localmente de "moitas".

As espécies que apresentaram maiores Valores de Uso para a comunidade do Palmital, sendo, portanto as mais 
Tabela 1. Espécies reconhecidas pelos moradores da comunidade do Palmital, município de Viçosa, Zona da Mata de Minas Gerais, como pertencentes às formações florestais com suas respectivas famílias botânicas, espécie botânica, nome popular, usos atribuídos, partes utilizadas e Valor de Uso (VU). Os nomes locais e os usos mais citados estão destacados em negrito.

\begin{tabular}{|c|c|c|c|c|c|}
\hline Família & Espécie & Nome popular & Usos & Parte & $\mathbf{V u}$ \\
\hline \multicolumn{6}{|c|}{ ANACARDIACEAE } \\
\hline & Schinus terebinthifolius Raddi & Aroeira/ Aroeirinha & estaca, esteio, lenha, móveis, tábua & caule, madeira & 0,5 \\
\hline & Tapirira marchandii Engl. & Cedrin & móveis, tábua & madeira & 0,08 \\
\hline \multicolumn{6}{|c|}{ ANNONACEAE } \\
\hline & Annona cacans Warm. & $\begin{array}{l}\text { Articum ou Jacarandá- } \\
\text { amarelo }\end{array}$ & $\begin{array}{l}\text { cabo de enxada, comer, estaca, lenha, moldura, } \\
\text { ripa, tábua }\end{array}$ & caule, fruto, madeira & 0,5 \\
\hline & Guatteria nigrescens Mart. & Pindaíba & cabo de enxada, caibro, régua, ripa & caule, madeira & 0,2 \\
\hline & Xylopia sericea A.St.-Hil. & Pimenteira & $\begin{array}{l}\text { cabo de enxada, cabo de ferramenta, caibro, } \\
\text { construção, estaca, esteio, lenha, madeira, peça de } \\
\text { construção, régua, ripa, tábua, travessa, viga de } \\
\text { caibro }\end{array}$ & caule, madeira & 1,92 \\
\hline
\end{tabular}

\begin{tabular}{|c|c|c|c|c|c|}
\hline \multicolumn{6}{|l|}{ APOCYNACEAE } \\
\hline & Aspidosperma polyneuron Müll. Arg. & Peroba & $\begin{array}{l}\text { caibro, estaca, esteio, lenha, mesa, móveis, régua, } \\
\text { ripa, tábua }\end{array}$ & caule, madeira & 0,62 \\
\hline & Aspidosperma subincanum Mart. & Tambú & $\begin{array}{l}\text { cabo de enxada, cabo de ferramenta, cabo de } \\
\text { foice, cabo de machad o, cabo de martelo, estaca, } \\
\text { lenha, móveis, régua, ripa, tábua }\end{array}$ & caule, madeira & 0,46 \\
\hline & Tabernaemontana laeta Mart. & Pau-de-leite & proteção para carro-de-boi & caule & 0,04 \\
\hline \multicolumn{6}{|l|}{ ARECACEAE } \\
\hline & Cocos nucifera $\mathrm{L}$. & Coqueiro & Comer & fruto, gema & 0,12 \\
\hline & Euterpe edulis Mart. & Palmito ou Jussara & $\begin{array}{l}\text { caibro, comer, comer o palmito, pássaro comer, } \\
\text { ripa }\end{array}$ & $\begin{array}{l}\text { caule, fruto, gema, } \\
\text { madeira }\end{array}$ & 0,23 \\
\hline \multicolumn{6}{|l|}{ ASTERACEAE } \\
\hline & Baccharis sp. 1 & Alecrim-do-campo & Vassoura & toda a planta & 0,08 \\
\hline & Eupatorium sp. & $\begin{array}{l}\text { Assa-peixe ou } \\
\text { Camburá }\end{array}$ & chá, estaca, lenha, produção de mel & caule, flor, folha & 0,35 \\
\hline & Piptocarpha macropoda (DC.) Baker & Cafufu ou Pau-de-fumo & Lenha & caule & 0,04 \\
\hline & $\begin{array}{l}\text { Vanillosmopsis erythropappa (DC.) Sch. } \\
\text { Bip. }\end{array}$ & Candeia & Estaca & caule & 0,04 \\
\hline & Vernonia diffusa Less. & Pau-de-fumo & caibro, lenha, régua, ripa & caule, madeira & 0,23 \\
\hline \multicolumn{6}{|l|}{ BIGNONIACEAE } \\
\hline & $\begin{array}{l}\text { Handroanthus chrysotrichus (Mart. ex } \\
\text { A.DC.) Mattos }\end{array}$ & Pau-mulato & $\begin{array}{l}\text { cabo de enxada, cabo de ferramenta, cabo de } \\
\text { machado, chicote,estaca, freio de carro -de-boi, } \\
\text { fuleiro de carro-de-boi, guiada para a criação }\end{array}$ & caule, madeira & 0,62 \\
\hline & $\begin{array}{l}\text { Handroanthus impetiginosus (Mart. ex } \\
\text { DC.) Mattos }\end{array}$ & Ipê- roxo & caibro, estaca, esteio, ornamental, ripa, tábua & $\begin{array}{l}\text { caule, madeira, toda } \\
\text { a planta }\end{array}$ & 0,23 \\
\hline & $\begin{array}{l}\text { Handroanthus serratifolius (Vahl) S. O. } \\
\text { Grose }\end{array}$ & Ipê-amarelo & caibro, estaca, esteio, ornamental, ripa, tábua & $\begin{array}{l}\text { caule, madeira, toda } \\
\text { a planta }\end{array}$ & 0,23 \\
\hline & Jacaranda macrantha Cham. & Caroba & cabo de foice, cabo de machado & caule & 0,08 \\
\hline & Pyrostegia venusta (Ker Gawl.) Miers & Cipó-de-são joão & amarrar cerca, cerca, produção de mel & caule, flor & 0,12 \\
\hline & $\begin{array}{l}\text { Sparattosperma leucanthum (Vell.) } \\
\text { K.Schum. }\end{array}$ & Cinco-folhas & $\begin{array}{l}\text { depurativo do sangue, estaca, lenha, medicinal, } \\
\text { ripa, tábua }\end{array}$ & caule, folha, madeira & 0,27 \\
\hline & Tynanthus sp. & Cipó-cravo & curtir a cachaça, lenha & casca, caule & 0,12 \\
\hline \multicolumn{6}{|l|}{ BOMBACACEAE } \\
\hline & Ceiba speciosa (A. St.-Hil.) Ravenna & Paineira & Beleza & toda a planta & 0,08 \\
\hline \multicolumn{6}{|l|}{ BORAGINACEAE } \\
\hline & Cordia sellowiana Cham. & Grão-de-galo & Lenha & caule & 0,04 \\
\hline \multicolumn{6}{|l|}{ BURSERACEAE } \\
\hline & Trattinnickia ferruginea Kuhlm. & Mamoneira & caibro, móveis, porta, ripa, tábua & caule, madeira & 0,46 \\
\hline \multicolumn{6}{|c|}{ CAESALPINACEAE } \\
\hline & Apuleia leiocarpa (Vogel) J.F.Macbr. & Garapa & $\begin{array}{l}\text { caibro, canzio de canga } \text {-de-boi, carro -de-boi, } \\
\text { cerca, eixo de carro -de-boi, estaca, esteio, lenha, } \\
\text { madeira, mourão, móveis, régua, ripa, tábua }\end{array}$ & caule, madeira & 2,23 \\
\hline & Caesalpinia echinata Lam. & Pau-brasil & dormente de linha de ferro, esteio & caule, madeira & 0,12 \\
\hline & Copaifera langsdorffii Desf. & Pau-de-óleo & $\begin{array}{l}\text { caibro, carro -de-boi, curtir a cachaça, estaca, } \\
\text { esteio, lenha, móveis, régua, ripa, tábua }\end{array}$ & $\begin{array}{l}\text { Casca do caule, } \\
\text { caule, madeira }\end{array}$ & 0,62 \\
\hline & Hymenaea courbaril $\mathrm{L}$. & Jatobá & caibro, lenha, móveis, régua, ripa, tábua, vinho & $\begin{array}{l}\text { caule, exudado, } \\
\text { madeira }\end{array}$ & 0,46 \\
\hline & Melanoxylon brauna Schott & Braúna & estaca, esteio, lenha, tábua & caule, madeira & 0,73 \\
\hline & $\begin{array}{l}\text { Senna macranthera (DC. ex Collad.) H.S. } \\
\text { Irwin \& Barneby }\end{array}$ & Fedegoso & Estaca & caule & 0,04 \\
\hline & Schizolobium parahyba (Vell.) S.F.B lake & Fava-de-santo & Artesanato & semente & 0,04 \\
\hline \multicolumn{6}{|l|}{ CLUSIACEAE } \\
\hline & Rheedia gardneriana Planch. \& Triana & Bacupari & Comer & fruto & 0,12 \\
\hline & Vismia brasiliensis Choisy & Ruão & $\begin{array}{l}\text { cabo de enxada, caibro, canzio de canga-de-boi, } \\
\text { cerca, estaca, lenha, ripa }\end{array}$ & caule, madeira & 0,58 \\
\hline & Vismia guianensis (Aubl.) Pers. & Ruão & $\begin{array}{l}\text { cabo de enxada, caibro, canzio de canga-de-boi, } \\
\text { cerca, estaca, lenha, ripa }\end{array}$ & caule, madeira & 0,58 \\
\hline
\end{tabular}

Sitientibus série Ciências Biológicas 11(2): 265-278. 2011. 
G. T. Soldati et al. - Etnobotânica em uma comunidade rural: base para conservação

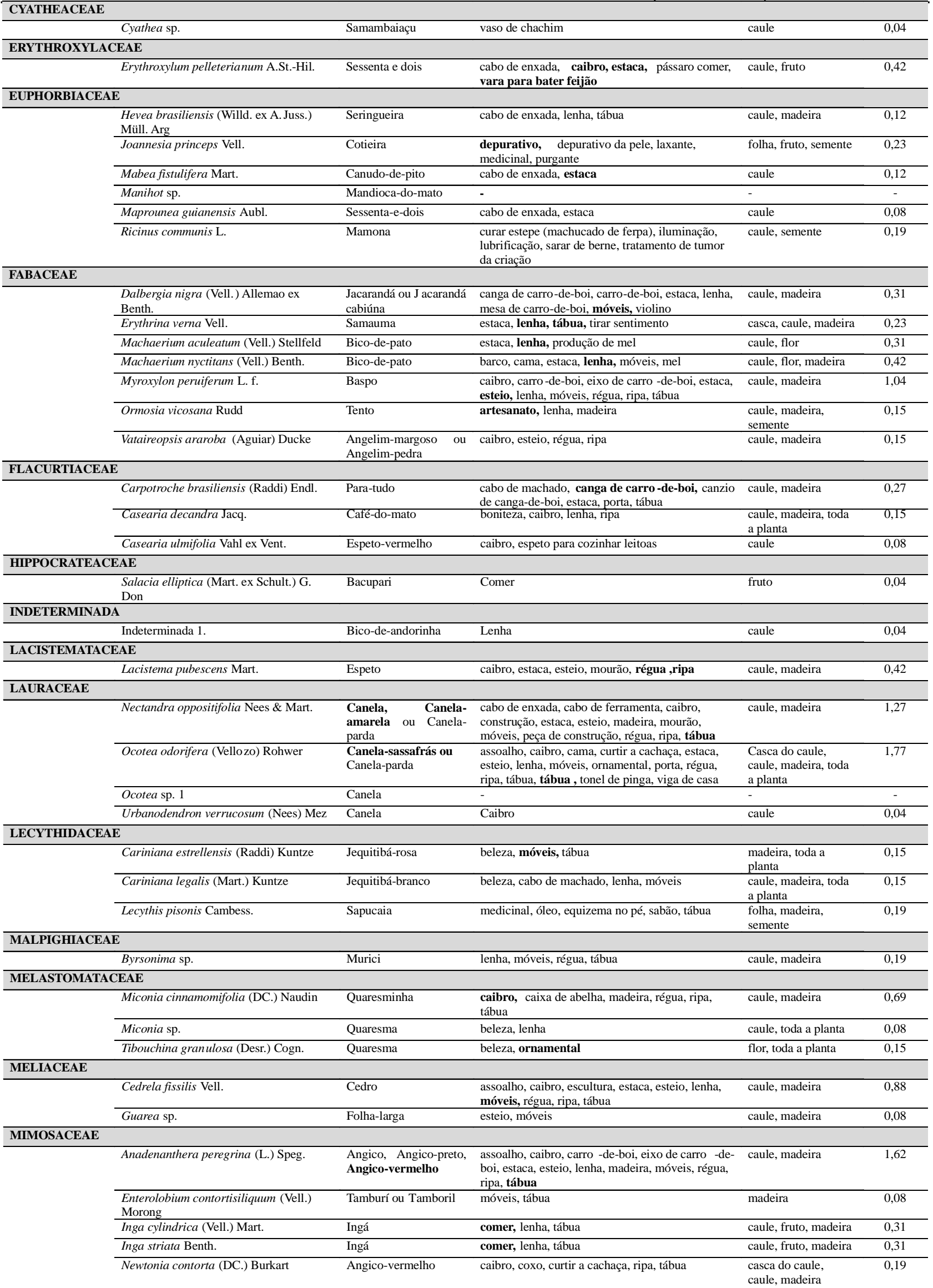


G. T. Soldati et al. - Etnobotânica em uma comunidade rural: base para conservação

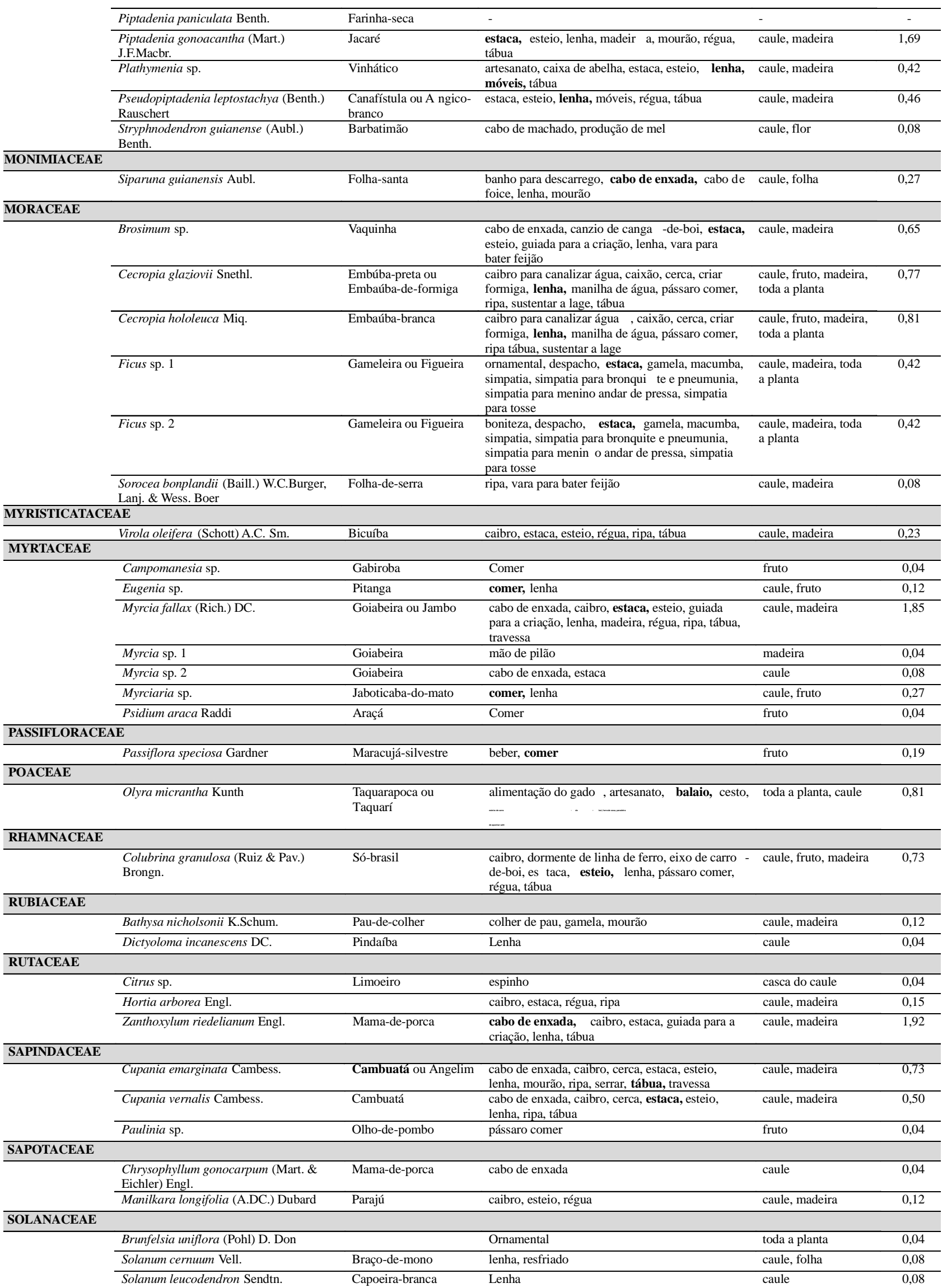

Sitientibus série Ciências Biológicas 11(2): 265-278. 2011. 
G. T. Soldati et al. - Etnobotânica em uma comunidade rural: base para conservação

\begin{tabular}{|c|c|c|c|c|c|}
\hline \multicolumn{6}{|l|}{ TILIACAEA } \\
\hline & Luehea grandiflora Mart. & Açoita-cavalo & $\begin{array}{l}\text { enrolar cabelo, estaca, lenha, tábua, tratamento } \\
\text { de cabelo }\end{array}$ & $\begin{array}{l}\text { casca do caule, } \\
\text { caule, exudado, } \\
\text { madeira }\end{array}$ & 0,23 \\
\hline & Aegiphyla sellowiana Cham. & Papagaio & acabar com os piolhos, estaca, lenha, óleo & caule, semente & 0,46 \\
\hline & Aloysia virgata (Ruiz \& Pav.) Juss. & Santa-cruz & - & - & - \\
\hline & Vitex polygama Cham. & Maria-preta & $\begin{array}{l}\text { cabo de ferramenta, caibro, comer, estaca, guiada } \\
\text { para a criação, lenha, reio para animal }\end{array}$ & caule, fruto & 0,38 \\
\hline \multicolumn{6}{|l|}{ SEM COLETA } \\
\hline & sem coleta 1 & Brauninha & estaca, lenha, mourão & caule & 0,12 \\
\hline & sem coleta 2 & Caituá & $\begin{array}{l}\text { cabo de enxada, cabo de ferramenta, caibro, } \\
\text { comer, régua, ripa }\end{array}$ & caule, fruto, madeira & 0,23 \\
\hline & sem coleta 3 & Castanheira & estaca, régua, tábua & caule, madeira & 0,12 \\
\hline & sem coleta 4 & Esperta & Lenha & caule & 0,04 \\
\hline & sem coleta 5 & Guarita & comer, estaca, esteio, móveis, tábua & caule, fruto, madeira & 0,19 \\
\hline & sem coleta 6 & Jacarandá-branco & cabo de enxada, canga de carro-de-boi, lenha & caule, madeira & 0,12 \\
\hline & sem coleta 8 & Liquerana & barco, lenha & caule, madeira & 0,08 \\
\hline & sem coleta 9 & Navalha-de-macaco & pegar na gente & folha & 0,04 \\
\hline & sem coleta 10 & Puleiro-de-anú & Lenha & caule & 0,04 \\
\hline & sem coleta 11 & Sacupema & caixa & caule, madeira & 0,08 \\
\hline & sem coleta 12 & Sucupira & lenha, móveis, roda de carro-de-boi & caule, madeira & 0,15 \\
\hline & sem coleta 13 & Tajuba & $\begin{array}{l}\text { caibro, carro-de-boi, eixo de carro -de-boi, estaca, } \\
\text { esteio, lenha, móveis, régua, tábua }\end{array}$ & caule, madeira & 0,46 \\
\hline
\end{tabular}

consensuais, foram: Apuleia leiocarpa (Vogel) J.F.Macbr. (garapa, VU =2,23), Xylopia sericea A.St.-Hil. (pimenteira, $\mathrm{VU}=1,92$ ), Myrcia fallax (Rich.) DC. (goiabeira ou jambo, VU $=1,84)$, Ocotea odorifera (Vell.) Rohwer (canelasassafrás, VU = 1,76) e Piptadenia gonoacantha (Mart.) J.F.Macbr. (jacaré, VU = 1,69).

Aloysia virgata (Ruiz \& Pav.) Juss. (santa-cruz), Manihot sp. (mandioca-do-mato), Ocotea sp.1 (canela), Piper lepturum (Kunth) C.DC. (jaborandi), Piptadenia paniculata Benth. (farinha-seca), Gallesia sp. (pau-d'alho), Trema micrantha (L.) Blume (quindiuba) são as sete plantas que não receberam qualquer citação de uso. Eupatorium sp. foi a espécie que apresentou a maior versatilidade, foi citada em cinco categorias de usos distintas: alimentação, combustível, construção, medicinal e outros. Nenhuma espécie apresentou citações de uso em todas as categorias.
Os totais de uso por espécies encontrado neste trabalho seguem a mesma tendência de outras investigações (e.g., Phillips \& Gentry 1993a), com muitas espécies apresentando poucos usos e poucas espécies tendo muitos usos. Vinte e oito espécies apresentaram apenas um uso, como foi o caso de Solanum leucodendron Sendtn. (capoeira-branca) que serve para "lenha", Chrysophyllum gonocarpum (Mart. \& Eichler) Engl. (mama-de-porca) que serve para "cabo de enxada" e Brunfelsia uniflora (Pohl) D. Don que foi indicada apenas como "ornamental".

Ocotea odorifera é a espécie que mais apresenta usos distintos, 16 no total, distribuídos nas categorias construção, combustível, tecnologia e outros. Em seguida, aparece Xylopia sericea e Apuleia leiocarpa, ambas com 15 usos distintos nas categorias combustível, tecnologia e construção. Essas três últimas espécies citadas se encontram

Tabela 2. Total de espécies, espécies exclusivas, usos e citações por Categoria de Uso. Valor de Uso e porcentagem de contribuição no Valor de Uso total para cada Categoria de Uso registrada na comunidade do Palmital, município de Viçosa, Zona da Mata de Minas Gerais, Brasil.

\begin{tabular}{lcccccc} 
Categoria de Uso & $\begin{array}{c}\text { Espécies } \\
(\boldsymbol{\%})\end{array}$ & $\begin{array}{c}\text { Espécies } \\
\text { exclusivas }\end{array}$ & $\begin{array}{c}\text { Total de } \\
\text { usos }(\%)\end{array}$ & $\begin{array}{c}\text { Total de } \\
\text { citações } \\
(\%)\end{array}$ & $\begin{array}{c}\text { Valor de } \\
\text { Uso }\end{array}$ & $\begin{array}{c}\text { \% no VU } \\
\text { total }\end{array}$ \\
\hline Construção & $94(72,9)$ & $16(36,4)$ & $36(31,3)$ & $739(66,0)$ & 0,30237 & 65,98 \\
\hline Medicinal & $15(11,6)$ & $1(2,3)$ & $24(20,8)$ & $42(3,7)$ & 0,10769 & 3,75 \\
\hline Alimentação & $19(14,8)$ & $6(13,6)$ & $5(4,3)$ & $47(4,2)$ & 0,09514 & 4,20 \\
\hline Artefatos & $52(40,3)$ & $6(13,6)$ & $33(28,7)$ & $115(10,2)$ & 0,08506 & 10,27 \\
Combustível & $63(48,8)$ & $7(15,9)$ & $4(3,5)$ & $133(11,8)$ & 0,08120 & 11,88 \\
\hline Outros & $31(24,0)$ & $8(18,2)$ & $13(11,3)$ & $44(3,9)$ & 0,05459 & 3,93 \\
\hline Total & - & 44 & 115 & 1120 & - & 100 \\
\hline
\end{tabular}


Tabela 3. Totais de citações de uso, usos e espécies por parte utilizada na comunidade do Palmital, Viçosa, Zona da Mata de Minas Gerais, Brasil.

\begin{tabular}{lccc|}
\hline Parte utilizada & Citações & Usos & Espécie \\
\hline caule & 587 & 40 & 103 \\
\hline madeira & 401 & 37 & 78 \\
fruto & 50 & 12 & 21 \\
toda a planta & 26 & 9 & 17 \\
\hline semente & 15 & 8 & 9 \\
folha & 14 & 5 & 7 \\
casca & 12 & 5 & 6 \\
\hline flor & 9 & 3 & 6 \\
gema & 3 & 2 & 2 \\
exudado & 2 & 2 & 2 \\
\hline sapopema & 1 & 1 & 1 \\
\hline
\end{tabular}

entre as quatro primeiras posições da lista ordenada pelo Valor de Uso.

As espécies que são mais variadas em relação às partes utilizadas são: Cecropia glaziovii Snethl. ("embaúba-preta" ou "embaúba-de-formiga") e C. hololeuca Miq. ("embaúbabranca"), tendo usos atribuídos ao caule, fruto, madeira e "toda planta", e Euterpe edulis Mart. ("palmito" ou "jussara"), que tem o caule, fruto, madeira e gema utilizados. Essas três últimas espécies também se destacam pelo seu Valor de Uso.

O conhecimento está diferentemente distribuído na comunidade do Palmital, pois os informantes afirmam que as mulheres não conhecem tanto das coisas da "mata" quanto os homens. Essa diferença pode ser explicada pela função que a mulher exerce nessas comunidades, assumindo as atividades caseiras e em poucas situações, ou nunca, vão à "mata". Esse mesmo padrão foi encontrado em vários trabalhos (Phillips \& Gentry 1993a; Galeano 2000; Lucena et al. 2007; Lawrence et al. 2005) e tem sido justificado com os mesmos argumentos. Esse resultado corrobora a hipótese de existir um conhecimento especializado entre homens e mulheres.

As turnês-guiadas permitiram constatar que os odores das folhas e das cascas são também utilizados para o reconhecimento da árvore. Quanto à classificação, as árvores podem ser de "madeira branca" ("sem cerne"), "madeira amarela" e "madeira preta" ("de cerne"). Contudo, essa classificação não é muito difundida entre os moradores, estando ela vinculada aos conhecedores dos usos madeireiros, uma vez que as características utilizadas nesse sistema são dureza, peso e durabilidade da madeira. As "madeiras pretas" são mais valoradas e utilizadas para fins especiais, como esteio e eixo de carro-de-boi, enquanto as "madeiras brancas" são indicadas para atributos menos específicos e que não necessitam de características distintivas, como lenha, régua e ripa.

A situação do conhecimento torna-se ainda mais delicada quando se examina a transmissão oral na comunidade. No Palmital, 16 informantes (15 homens), relataram que a principal forma de aprendizado foi através de caminhadas na "mata" acompanhados dos pais ou parentes, principalmente para coletar recursos. Entretanto, nove informantes apontaram que a mudança de costumes relacionados a impossibilidade da caça, coleta e passeio na "mata", está comprometendo o conhecimento das futuras gerações. Outras formas de aprendizado citadas com menor frequência foram: "outros parentes" (tios e avós), as próprias experiências na vida, e a "escola".

Quando indagados se os filhos tinham interesse no conhecimento das coisas da "mata", quinze informantes responderam que sim, enquanto 14 afirmaram que não, o que compromete a perpetuação do conhecimento construído. Aqueles que responderam negativamente justificaram evidenciando mudanças de valores da realidade rural para a urbana, como: "Estão querendo outras formas de lazer, como a TV e o game." e "As cabeças estão mudando demais. Hoje eles querem estudar, querem outros tipos de conhecimento."

A comunidade do Palmital acredita que o conhecimento está concentrado em dois homens idosos (70 e 66 anos) que nasceram e viveram no local. Outros moradores não são tidos como referências no assunto, apesar de também portarem conhecimento significativo. Essa situação pode ser explicada por uma desarticulação interna entre os moradores, provavelmente pela falta de ambientes e eventos sociais importantes na socialização e difusão do conhecimento, fato também evidenciado por Albuquerque (2002). O rico conhecimento que essas duas referências carregam pode ser facilmente perdido, a exemplo da morte de um raizeiro local, conhecedor das propriedades terapêuticas de muitas plantas.

As plantas medicinais, de eficácia legitimada pelo conhecimento local, baixos custos e fácil acesso são um elo entre o ambiente e a cultura e estão vinculadas a uma questão vital: a saúde. Contudo, como afirmado anteriormente, no Palmital, a EPTEA não é reconhecida localmente como fonte de muitos recursos medicinais. Poucas pessoas sabem dos remédios existentes nas matas nativas. As entrevistas permitiram perceber que existe uma desconfiança nestes remédios, principalmente pela incerteza na maneira de utilizá-los. Entretanto, alguns moradores relataram que se tivessem como acessar um bom conhecedor ou ter garantia das plantas e das posologias, prefeririam fazer uso desses recursos em vez dos remédios sintéticos. Pelas entrevistas, percebeu-se que antigamente era comum a utilização de plantas na cura e tratamento de males.

Percepções dos parceiros da pesquisa em relação ao fragmento de mata e seus aspectos ecológicos. $\mathrm{O}$ histórico absorvido pelas entrevistas permitiu concluir que antigamente os moradores passeavam, andavam, caçavam e coletavam na Mata do Paraíso, atividades comuns na vida cotidiana. Entretanto, apesar desse histórico e da noção construída pela comunidade do Palmital, a "mata" não é mais entendida como um espaço "comunal", um local onde todos podem passear e explorar. Ou seja, as respostas 
evidenciam que a "mata" hoje não mais lhes pertence, foi expropriada, em parte pelas leis e órgão ambientais e pela universidade.

$\mathrm{O}$ processo de herança da terra, o qual comumente reduz progressivamente a propriedade individual a cada geração, também influenciou a comunidade junto com os outros aspectos. Dos 23 informantes que herdaram a propriedade, 13 afirmaram que a terra herdada é insuficiente, "pouca para sustentar a família". Os efeitos dessas pressões tornam-se evidentes quando se analisa os aspectos relacionados às questões do trabalho, o que certamente atinge as relações sociais. Nesse sentido, apesar da herança cultural, algumas falas evidenciaram que as atividades agrícolas assumiram um caráter pejorativo e perderam a importância que tinham ao não serem entendidas como atividades que garantem a autonomia, mas apenas como um resquício dos antepassados. Essa noção também é fortemente influenciada pela desvalorização econômica do meio rural. Outra evidência é a desestruturação do trabalho familiar. Três informantes afirmam que passam dificuldades pela ausência das relações familiares na produção, pois os filhos, que teriam esse papel, mudaram para o centro urbano para buscar emprego. Como resultante destes aspectos, as atividades assalariadas foram identificadas como o fundo que garante o "bem viver" mais importante (13 informantes), realidade diferente daquela que se projeta para uma comunidade rural.

Diegues (2002) afirmou que, para os moradores, a apropriação dos espaços comunais pode ser entendida como um "roubo" do seu território, afetando negativamente a estrutura social como um todo, enquanto Lawrence et al. (2005) evidenciaram que, nas comunidades estudadas, as leis são tidas como um obstáculo na perpetuação da vida cotidiana. Entretanto, na percepção da comunidade do Palmital, as mudanças deram-se no sentido de legitimar as leis ambientais. A grande maioria dos informantes concorda com as leis impostas sobre a utilização dos recursos naturais, justificando-se pelas drásticas mudanças ambientais, como a redução das "matas", e pelo uso não racional dos recursos.

As leis e a atuação da universidade podem ter sido geradas com o intuito de conservação da biodiversidade, mas na situação investigada estão degradando a diversidade cultural e distanciando a relação dos moradores com a natureza, ao bloquearem alguns processos intrínsecos de manutenção cultural. Adicionando o efeito dos aspectos econômicos e a redução da terra pela herança, o conhecimento local da comunidade do Palmital, fruto desses processos, está ameaçado.

Todos reconheceram ser importante conhecer as coisas da "mata"; a maioria (18 informantes), pela simples importância de se conhecer, porém oito deles atribuíram a este conhecimento sua maior segurança e autonomia, somadas à possibilidade de um uso mais racional dos recursos.
A grande maioria (92\%) dos informantes evidenciou que as "matas" poderiam ainda ser fontes de recursos e/ou ser usadas para gerar renda, favorecendo a autonomia dos moradores. Existe uma discussão em relação à necessidade de se aliar o uso dos recursos por populações locais e a conservação desses recursos (Albuquerque 2005). Iniciativas que visam a conservação dos recursos e que levam em consideração as necessidades locais de uso dos mesmos tendem a ser mais promissoras, uma vez que determinadas populações inevitavelmente os manejam e são também responsáveis pelas transformações ambientais (Bell 2001).

A grande maioria (18 informantes) disse que a "mata" é um lugar de muitas árvores, de diferentes "qualidades"; quatro disseram que a "mata" é as próprias árvores, onze moradores também afirmaram que "mata" é um lugar de "muitos bichos" e sete disseram que a "mata" é a "proteção para os bichos". Outros termos citados com menor frequência foram: "lugar de muita sombra", "lugar fechado", "fresquinha", "saudável" e "vida". Quando perguntados sobre a "mata", $46 \%$ dos informantes responderam imediatamente que ela deveria ser preservada. Esse dado contrasta com os resultados apresentados acima, nos quais os entrevistados indicam o fragmento florestal como fonte de recursos, indicando que o discurso conservacionista não condiz com as atividades de exploração da mata. Nas ciências humanas, defende-se que este discurso é fruto de questões ideológicas (ideias, pensamentos, juízos e valores) que são construídos socialmente (Van Dijk 2008). Essas ideologias se tornam conflitantes quando esses grupos sociais se vêm obrigados a utilizar os recursos ambientais para atender suas necessidades de sobrevivência diária.

Além disso, todos afirmaram saber que a EPTEA está sob cuidado da Universidade Federal de Viçosa e que, devido às leis ambientais, não é permitido tomar posse de nenhum recurso disponível nas formações florestais. Analisando essas questões, se faz necessário questionar se houve uma mudança pautada em uma nova compreensão ambiental ou essas respostas refletiram algo mais, como a desestruturação dos valores sociais por pressões externas, evidenciado por Diegues (2000).

A análise do Discurso do Sujeito Coletivo da pergunta relacionada às representações dos diferentes aspectos ecológicos do fragmento de floresta realizada com os 26 informantes, assim como a comparação desse discurso com dados da literatura, é apresentada na Tabela 4. De acordo com essa análise, alguns aspectos ecológicos foram reconhecidos, como a diversidade de plantas, animais e fitofisionomias, além de interações entre espécies vegetais. O que já era esperado, visto que os informantes estão em contato direto com o ecossistema e seus processos ecológicos. Estudos etnobotânicos já têm demonstrado que populações locais detêm conhecimento sobre os recursos naturais, pois as mesmas manejam e os percebem diariamente (Silva \& Andrade 2005; Cunha \& Albuquerque 2006). 
Tabela 4. Cognição comparada entre informações dos moradores da comunidade do Palmital, município de Viçosa, Zona da Mata de Minas Gerais, Brasil, e citações da literatura sobre diferentes aspectos ecológicos reconhecidos na Mata do Paraíso.

\begin{tabular}{|c|c|c|}
\hline Ideia Central & Discurso do Sujeito Coletivo & Citações da Literatura \\
\hline Diversidade florística & $\begin{array}{l}\text { A mata é um lugar de muitas árvores, de diferentes qualidades, não } \\
\text { existe só a mata de madeira. Tem a samambaia, o capim de gordura, os } \\
\text { cipós, que tem de toda qualidade... existem várias matas dentro de uma } \\
\text { mata. Para ser mata tem que ter tudo completo. É tudo ligado. }\end{array}$ & $\begin{array}{l}\text { Em trabalho realizado na Floresta Estacional Semidecidual Montana } \\
\text { também no município de Viçosa-MG, realizou-se levantamento } \\
\text { fitossociológico, foram amostradas } 124 \text { espécies, distribuídas em } 180 \\
\text { gêneros e } 41 \text { famílias botânicas (Silva et al. 2004). Em outro trabalho } \\
\text { realizado nesse mesmo tipo de floresta, só que agora no município de } \\
\text { Lavras-MG, observou-se no levantamento florístico } 180 \text { espécies, } 113 \\
\text { gêneros e } 52 \text { famílias vegetais (Souza et al. 2007). }\end{array}$ \\
\hline Diversidade faunística & $\begin{array}{l}\text { A mata é um lugar de muitos bichos e sete disseram ser, a mata, a } \\
\text { proteção da fauna. }\end{array}$ & $\begin{array}{l}\text { Não foi encontrado na literatura, até o momento, dados sobre a } \\
\text { diversidade faunística nessa região. No entanto, existe um estudo } \\
\text { desenvolvido na região da Zona da Mata mineira que indicam a alta } \\
\text { diversidade de aves e insetos, por exemplo, (Ribon et al. 2004). }\end{array}$ \\
\hline \multirow[t]{2}{*}{ Competição } & $\begin{array}{l}\text { Tem madeiras que crescem mais, outras menos. Uma coladinha na } \\
\text { outra. Às vezes uma até atrapalha o crescimento da outra. É porque, no } \\
\text { campo, quando a gente vê duas árvores, quando é muito perto, elas } \\
\text { demoram mais a crescer. }\end{array}$ & $\begin{array}{l}\text { Muitos dos relatos de efeitos de plantas sobre o desenvolvimento das } \\
\text { outras têm sido classificados como competição e/ou alelopatia. O } \\
\text { que diferencia a alelopatia da competição entre plantas é o fato de que } \\
\text { esta competição reduzir ou remover do ambiente um fator de } \\
\text { crescimento necessário a ambas às plantas (luz, água, nutrientes, etc.), } \\
\text { enquanto a alelopatia ocorre pela adição de um fator direto ou indireto } \\
\text { ao meio e é um fenômeno que ocorre largamente em comunidades de } \\
\text { plantas (Souza Filho \& Alves 2000). }\end{array}$ \\
\hline & $\begin{array}{l}\text { Elas não gostam de ficar muito perto de muitas árvores, né? Ela costuma } \\
\text { dá muitos galhos ou costuma nascer fininha e crescer muito. A do meio } \\
\text { da mata ela quer, igual eu te falei, no lugar que ela nasce é sempre muito } \\
\text { esterco ela sempre quer passar as outras. Então lá em cima ela espicha e } \\
\text { abre mais, fica maior. E separada, ela pode desenvolver muito, mas de } \\
\text { repente ela não tem como desenvolver mais porque não tem muita } \\
\text { sombra em volta dela. }\end{array}$ & \\
\hline $\begin{array}{l}\text { Perda da } \\
\text { biodiversidade }\end{array}$ & $\begin{array}{l}\text { "A mata era fechada, tinha muito passarinho, tinha muito bicho bravo, } \\
\text { tinha onça, tinha tudo quanto é bicho... macaco nas árvores. Ocê tá nas } \\
\text { capoeiras fechadas um tá pulando de um galho para o outro... capoeira } \\
\text { fechada... jacu. Quantas pessoas não vão saber o que é uma preguiça? O } \\
\text { que era um macaco? Um gambá? Capoeira foi cabando, foi cabando } \\
\text { também, né? Os jacus vem comer no meu terreiro. Se existissem matas } \\
\text { ele não precisavam vir comer no terreiro, não era igual a eles que estão } \\
\text { quase domesticados. Porque o eucalipto, ocê sabe que acaba com os } \\
\text { frutos dos passarinhos, por que o eucalipto não dá semente para os } \\
\text { passarinhos. }\end{array}$ & $\begin{array}{l}\text { A quase totalidade da cobertura vegetal primitiva em Minas Gerais foi } \\
\text { reduzida a remanescentes esparsos, a grande maioria com menos de } \\
10 \text { ha (Nunes et al. 2002). A região de Viçosa apresenta uma paisagem } \\
\text { que mostra o confinamento das florestas em fragmentos, geralmente } \\
\text { em locais de difícil acesso à exploração ou guardados por } \\
\text { propriedades particulares (Silva et al. 2003). }\end{array}$ \\
\hline
\end{tabular}

As respostas também permitiram perceber o rico conhecimento que a comunidade apresenta sobre alguns processos ecológicos. Houve citações que sugeriram conhecimento sobre: competição entre árvores (2 citações); existência de fisionomias distintas que compõem o mosaico vegetacional que é a Mata do Paraíso (7), algumas vezes atribuídas a diferenças do solo ou umidade (2); a possível relação entre as formas de vida herbáceas e o potencial terapêutico (1); bioindicadores de ambientes mais úmidos e férteis (1); sucessão natural (1); fenômenos de extinção local (2); e interdependência dos elementos ambientais reconhecidos pelo parceiro na construção de um todo (6).

A partir dessa comparação observa-se que muito dos aspectos ecológicos do fragmento florestal relatados pelos entrevistados, já vêm sendo discutidos na literatura. Essas informações demonstram o vasto conhecimento dos informantes a cerca da ecologia, diversidade e comportamento de espécies vegetais e animais da área estudada. Por exemplo, a alta diversidade de espécies vegetais no fragmento estudado foi relatada e existem estudos fitosociológicos que corroboram esses resultados (Silva et al. 2004; Souza et al. 2007).

As fisionomias florestais são reconhecidas como "mata" ou "capoeira", sendo essa última designação também destinada às formações mais jovens e antropizadas. $\mathrm{O}$ conhecimento sobre esses espaços na paisagem está distribuído por toda a comunidade, e, quando agrupado e sistematizado revela significativa grandeza e detalhada percepção dos fenômenos ambientais, englobando aspectos locais e regionais, passando por grande parte dos elementos que compõem a natureza.

\section{Conclusões}

Considerando que as entrevistas focaram o conhecimento local sobre apenas uma das regiões reconhecidas localmente como zona de recursos, a Mata do Paraíso, percebe-se que a comunidade reúne muitas informações sobre os recursos vegetais, expresso pelo volume de espécies citadas, 134 ao todo. As citações de uso sugerem uma forte pressão sobre o fragmento, pois a categoria construção foi a mais importante localmente e as partes perenes das plantas, madeira e caule, as mais citadas. Entretanto, a vivência em campo permite afirmar que poucos eventos de exploração ainda ocorrem na Mata do Paraíso, 
situação construída principalmente pelas leis de proteção ambiental, das quais os moradores estão informados. Essa realidade sugere que não existe uma relação entre conhecimento local (uso potencial) e pressão de uso (extração propriamente dita).

As representações ambientais locais expressam diferentes percepções sobre os fragmentos. Os dos parceiros da pesquisa atribuíram muita importância à Mata do Paraíso, reconhecendo diversos serviços ambientais e a necessidade de sua conservação. Entretanto, as pressões sofridas pelos moradores, principalmente oriundas das leis ambientais, da inserção da Universidade, do processo de herança de terra e das mudanças dos valores locais, podem colocar em risco a perpetuação desse conhecimento e/ou modificar as representações locais.

Neste sentido, o presente texto reúne parte do conhecimento local sobre as formações florestais da região que deve ser utilizada na construção de uma gestão participativa da Mata do Paraíso. Essas propostas integrativas tendem a fortalecer o protagonismo social da comunidade do Palmital, tendo como ponto de partida a realidade local, uma vez que a organização social é um dos caminhos em prol da melhoria de vida das comunidades e preservação do meio ambiente. A participação dos moradores possibilitaria a redução de eventuais conflitos, além de propiciar e fomentar a reflexão sobre a situação ambiental na Zona da Mata Mineira.

\section{REFERÊNCIAS}

Albuquerque, U.P. 2002. Introdução à Etnobotânica. Bagaço, Recife.

Albuquerque, U.P. 2005. Etnobiologia e Biodiversidade. NUPEEA, Recife.

Albuquerque, U.P. 2006. Re-examining hypotheses concerning the use and knowledge of medicinal plants: a study in the Caatinga vegetation of NE Brazil. Journal of Ethnobiology and Ethnomedicine 2: 1-10.

Albuquerque U.P.; Lucena R.F.P. \& Alencar N.L. 2010a. Métodos e técnicas para coleta de dados etnobiológicos. In: U.P. Albuquerque, R.F.P. Lucena \& L.V.F.C. Cunha (eds), Métodos e Técnicas na Pesquisa Etnobiológica e Etnoecológica. Editora Livro Rápido/NUPEEA, Recife, p. 41- 72 .

Albuquerque, U.P.; Hanazaki, N. \& Melo, J.G. 2010 b. Problemas e perspectivas na publicação de trabalhos em etnobotânica e etnofarmacologia. In: U.P. Albuquerque, R.F.P. Lucena \& L.V.F.C. Cunha (eds), Métodos e Técnicas na Pesquisa Etnobiológica e Etnoecológica. Editora Livro Rápido/NUPEEA, Recife, p. 439-461.

Bell, S. 2001. Landscape pattern, perception and visualisation in the visual management of forests. Landscape and Urban Planning 54: 201-211.

Borges, R. \& Peixoto, A.L. 2009. Conhecimento e uso de plantas em uma comunidade caiçara do litoral sul do estado do Rio de Janeiro, Brasil. Acta Botanica Brasilica 23: 769-779.

Botrel, R.T.; Rodrigues, L.A.; Gomes, L.J.; Carvalho, D.A. \& Fontes, M.A.L. 2006. Uso da vegetação nativa pela população local no município de Ingaí, MG, Brasil. Acta Botanica Brasilica 20: 143-156.

Cavalcante, S. \& Maciel, R.H. 2008. Métodos de avaliação da percepção ambiental. In: J.Q. Pinheiro \& H. Günther (eds), Métodos de Pesquisa nos Estudos Pessoa-Ambiente. Casa do Psicólogo, São Paulo, p. 149-180.

Cronquist, A. 1988. The Evolution and Classification of Flowering Plants. New York Botanical Garden, New York.

Cunha, L.V.F.C. \& Albuquerque, U.P. 2006. Quantitative ethnobotany in an Atlantic Forest fragmento of Northeastern Brazil - implications to conservation. Environmental Monitoring and Assessment 114: 1-25.

Diegues, A.C. 2000. Etnoconservação da natureza: enfoques alternativos. In: A.C. Diegues (ed.). Etnoconservação: novos rumos para a proteção da natureza nos trópicos. Hucitec \& Nupaub-USP, São Paulo, p 120-138.

Diegues, A.C. 2002. O Mito Moderno da Natureza Intocada. Hucitec \& NUPAUB/USP, São Paulo.

Drummond, G.M.; Martins, C.S.; Machado, A.B.M.; Sebaio, F.A. \& Antonini, Y. 2005. Biodiversidade em Minas Gerais: um atlas para sua conservação. Fundação Biodiversitas, Belo Horizonte.

Galeano, G. 2000. Forest use at the Pacific Coast of Chocó, Colômbia: a quantitative approach. Economic Botany 54: 358 -376 .

Guerra, R.A.T. \& Abílio, F.J.P. 2005. A percepção ambiental de professores de escolas públicas de ensino fundamental de Cabedelo, Paraíba. In: F.J.P. Abílio \& R.A.T. Guerra (eds), A Questão Ambiental no Ensino de Ciências: a formação continuada de professores de ensino fundamental. UFPB/ FUNAPE, João Pessoa, p. 91-104.

Gumuchian, H.E. \& Marois, C. 2000. Initiation a la Recherche en Géographie, Aménagement, Développement Territorial, Environnement. Anthropos \& Presses de l'Université de Montréal, Paris \& Montreal.

Hanazaki, N.; Tamashiro, J.Y.; Leitão-Filho, H.F. \& Begossi, A. 2000. Diversity plants uses in two Caiçara communities from the Atlantic Forest coast, Brazil. Biodiversity and Conservation 9: 597-615.

Lawrence, A.; Phillips, O.L.; Reategui, A.; Lopez, M.; Rose, S.; Wood, D.E. \& Farfan, A.J. 2005. Local values for harvested forest plants in Madre de Dios, Peru: towards a more contextualised interpretation of quantitative ethnobotanical data. Biodiversity and Conservation 14: 4579.

Lefevre, F. \& Lefevre, A.M.C. 2005. Depoimentos e Discursos: uma proposta de análise em pesquisa social. Liber Livro, Brasília.

Lucena R.F.P.; Araújo E.L. \& Albuquerque U.P. 2007. Does the local availability of woody caatinga plants (Northeastern Brazil) explain their use value? Economic Botany 61: 347361.

Miranda, E.V.; Wantuelfer, G. \& Ribeiro, G.A. 1999. Projeto Mata do Paraíso, Viçosa, MG. Departamento de Engenharia Florestal, Universidade Federal de Viçosa, Viçosa.

Marques, J.G.W. 1993. Etnoecologia, educação ambiental e 
superação da pobreza em áreas de manguezais. In: Anais do Encontro Nacional de Educação Ambiental em Áreas de Manguezais. 1, Maragogipe, p. 29-35.

Mutchnick, P.A. \& McCarthy, B.C. 1997. An ethnobotanical analysis of the tree species common to the subtropical moist forest of the Peten, Guatemala. Economic Botany 51: 158183.

Nunes, Y. R.F.; Mendonça A.V.R.; Botezelli, L.; Machado, E.L.M. \& Oliveira-Filho, A.T. 2002. Variações da fisionomia, diversidade e composição de guildas da comunidade arbórea em um fragmento de floresta Semidecidual em Lavras, MG. Acta Botanica Brasilica 17: 213-229.

Phillips, O. \& Gentry, A.H. 1993a. The useful plants of Tambopata, Peru: I. Statistical hypotheses test with new quantitative technique. Economic Botany 47: 15-32.

Phillips, O. \& Gentry, A.H. 1993b. The useful plants of Tambopata, Peru: II. Additional hypothesis testing in quantitative ethnobotany. Economic Botany 47: 33-43.

Prefeitura de Viçosa 2011. A cidade, disponível em http:// www.vicosa.mg.gov.br/index.php?option=com_content\&vie $\mathrm{w}=$ article $\& \mathrm{id}=55 \&$ Itemid $=1$; acesso em 10 maio 2011 .

RBMA (Reserva da Biosfera da Mata Atlântica) 2010. Texto Síntese. Disponível em http://www.rbma.org.br/rbma/ rbma_1_textosintese.asp; acesso em 13 maio 2010.

Ribon, R.; Lamas, I.R. \& Gomes, H.B. 2004. Avifauna da Zona da Mata de Minas Gerais: municípios de Goianá e Rio Novo, com alguns registros para Coronel Pacheco e Juiz de Fora. Revista Árvore 28: 291-305.

Silva, A.F.; Oliveira, R.V.; Santos, N.R.L. \& De Paula, A. 2003. Composição florística e grupos ecológicos das espécies de um trecho de floresta Semidecídua Submontana da fazenda São Geraldo, Viçosa - MG. Revista Árvore 27: 311-319.

Silva, A.J.R. \& Andrade, L.H.C. 2005. Etnobotânica nordestina: estudo comparativo da relação entre comunidades e vegetação na zona do Litoral - Mata do Estado de Pernambuco, Brasil. Acta Botanica Brasilica 19: 45-60.

Silva, C.T. 2003. Dinâmica da Vegetação Arbórea de uma
Floresta Secundária no Município de Viçosa, Minas Gerais. Tese de Mestrado. Universidade Federal de Viçosa.

Silva, N.R.S.; Martins, S.V.; Meira-Neto, J.A.A. \& Souza, A.L. 2004. Composição florística e estrutura de uma floresta Estacional Semidecidual Montana em Viçosa, MG. Revista Árvore 1: 397-405.

Silva, T.C.; Medeiros, P.M.; Araújo, T.A.S. \& Albuquerque, U.P. 2010. Northeastern Brazilian students' representations of Atlantic Forest fragments. Environmental Development and Sustainability 12: 195-211.

Souza, F.N.; Araújo, E.J.G.; Mello, J.M.; Scolforo, J.R.S. \& Silva, C.P.C. 2007. Composição florística e estrutura de dois fragmentos de Floresta Estacional Semidecidual na Bacia do Rio Grande, Minas Gerais. Revista Brasileira de Biociências 5: 183-185.

Souza Filho, A.P.M. \& Alves, A.M. 2000. Potencial alelopático de plantas de acapu (Vouacapoua americana): efeitos sobre plantas daninhas de pastagens. Planta Daninha 18: 435441.

Toledo, V.M. 1992. What is ethnoecology? Origins, scope and implications of a rising discipline. Etnoecologica 1: 5-21.

Valverde, O. 1958. Estudo regional da Zona da Mata de Minas Gerais. Revista Brasileira de Geografia 20: 1-82.

Van Dijk, T.A. 2008. Semántica del discurso e ideologia. Discurso \& Sociedad 2: 201-261.

Veloso , H.P.; Rangel Filho, A.L.R. \& Lima, J.C.A. 1991. Classificação da Vegetação Brasileira Adaptada a um Sistema Universal. IBGE, Rio de Janeiro.

Viertler, R.B. 2002. Métodos antropológicos como ferramenta para estudos em etnobiologia e etnoecologia. In: M.C.M. Amorozo, L.C. Ming \& S.M.P. Silva (eds), Métodos de Coleta e Análise de Dados em Etnobiologia, Etnoecologia e Disciplinas Correlatas. CNPq/UNESP, Rio Claro, p. 11-30.

Yildiz, A. 1994. Local representations and management of agroforest on the periphery of Kerlnci Seblat National Park, Sumatra, Indonesia. People and Plants Working Paper. Vol. 3. Unesco, Paris. 